Larsen, T. A., Maurer, M., Udert, K. M., \& Lienert, J. (2007). Nutrient cycles and resource management: implications for the choice of wastewater treatment technology. water Science and Technology, 56(5), 229-237. https://doi.org/10.2166/wst.2007.576

\title{
Nutrient Cycles and Resource Management: Implications for the Choice of Wastewater Treatment Technology
}

\author{
Tove A. Larsen, Max Maurer, Kai M. Udert, Judit Lienert
}

Eawag, Swiss Federal Institute of Aquatic Science and Technology, 8600 Dübendorf, Switzerland (E-mails: larsen@eawag.ch; max.maurer@eawag.ch; kai.udert@eawag.ch; judit.lienert@eawag.ch)

\begin{abstract}
We look at the most important issues of the global nitrogen and phosphorus cycle and conclude that the nutrients from human metabolism are of no importance for the global nitrogen cycle and of minor importance for the global phosphorus cycle. However, for water pollution control, $\mathrm{N}$ and $\mathrm{P}$ from the human metabolism are of extreme importance. Nitrogen is mainly an issue for coastal waters, whereas $\mathrm{P}$ is an issue for freshwater and coastal areas alike. It is by now generally recognized that coastal ecosystems are exceedingly important for human well-being and at the same time highly endangered. The recycling issue is of high importance in areas where nutrient application is low due to economic constraints. NoMix technology (urine source separation) holds a large promise to become an efficient mainstream technology. The largest shortterm potential is found in densely populated areas in coastal areas without existing infrastructure and in areas with nutrient deficiency, especially in urban areas with a large nutrient potential. We believe, however, that these technologies will with time also become competitive in Europe.
\end{abstract}

Keywords nutrients, coastal areas, sustainability, urine source separation, wastewater treatment

\section{INTRODUCTION}

Despite ever stricter nutrient emission standards for wastewater in Europe, we observe a tendency to consider nutrients from wastewater of minor importance for the environment compared with nutrients from agriculture and energy production (see e.g. Harremöes, 1998; Kroiss, 2004). Raising doubt on the significance of nutrients from wastewater obviously questions the relevance of newer source separating approaches, which are mainly motivated by advanced nutrient management. In this paper, we review the contemporary discussion on nitrogen and phosphorus with respect to resources, environmental policy, and sustainable development. We also compare one new approach in wastewater management, the NoMix technology, with conventional end-of-pipe solutions.

\section{THE NITROGEN CYCLE}

Based on available data and a mechanistic understanding of the nitrogen cycle, Galloway et al. (2004) estimate the global fluxes of nitrogen. In Table 1 we summarize the aspects most relevant for the discussion of advanced nutrient management. The nitrogen metabolized by humans $\mathrm{N}_{\mathrm{mh}}$ amounts to $5 \%$ of the total production of reactive nitrogen $\mathrm{N}_{\mathrm{r}}\left(\mathrm{N}_{\mathrm{r}}\right.$ comprises all nitrogen compounds apart from $\mathrm{N}_{2}$ ). $\mathrm{N}_{\mathrm{mh}}$ is obviously irrelevant for the global nitrogen cycle with its high natural and anthropogenic turnover rates. Compared to the $\mathrm{N}_{\mathrm{r}}$ produced in the Haber-Bosch process, $\mathrm{N}_{\text {mh }}$ makes up $20 \%$, which is already more significant. From a resource point of view, the availability of $\mathrm{N}_{\mathrm{r}}$ is a question of energy and economy, two aspects we will discuss later in the paper. However, due to the large net losses of nitrogen in agriculture, uptake efficiency and hence the type of nitrogen fertilizer that might be produced from human waste is a highly important issue.

In order to understand the global nitrogen aspects of water pollution control, we compare the amount of metabolized nitrogen, $\mathrm{N}_{\mathrm{mh}}$ with the total flux of nitrogen from the continents to estuaries and shelves. Globally, $\mathrm{N}_{\mathrm{mh}}$ corresponds to $35-40 \%$ of this total flux, a potentially significant contribution to nitrogen pollution of coastal waters. The actual contribution, of course, depends on the transformation processes between production and sink. In contrast and again based on Table 1, 
we assume that the numerous other nitrogen transformations resulting e.g. in air pollution and greenhouse gas formation are dominated by the much larger non-wastewater sources. We therefore concentrate on coastal areas where wastewater nitrogen is most likely to cause problems (Galloway et al., 2003).

Table 1 Some aspects of the global nitrogen cycle ( $\mathrm{Mt}_{\mathrm{N}} / \mathrm{year}$; according to Galloway et al., 2004)

\begin{tabular}{lrrr} 
& 1860 & Early 1990s & 2050 \\
\hline Total production of reactive nitrogen $\left(\mathrm{N}_{\mathrm{r}}\right)$ & 262 & 389 & 492 \\
Haber-Bosch process (1990s: 86 \% for fertilizers) & 0 & 100 & 165 \\
Total flux to continents (natural + anthropogenic) & 135 & 238.5 & 313 \\
Nitrogen metabolized by humans, $\mathrm{N}_{\mathrm{mh}}\left(^{*}\right)$ & 4.7 & 20 & 37 \\
Flux to estuaries and shelves: & & 48 & 63.2 \\
$\quad$ Flow from continent & 27 & 8.4 & 17.1 \\
$\quad$ Atmospheric deposition & 1.4 & & \\
\hline
\end{tabular}

$\left.{ }^{\star}{ }^{\star}\right)$ Numbers correspond to $10 \mathrm{~g} \mathrm{~N} /$ person/day, an early 1990 population of 5.5 billion and a 2050 population of 10 billion.

There are many single studies on the actual contribution of wastewater to the nitrogen loading of coastal areas. The European Environment Agency (2005) concludes that in Europe, agriculture is the main source of nitrogen. This result is not surprising given the high degree of advanced nutrient removal in Europe and the intensive agriculture. However, recently Valiela et al. (2002) concluded that the results of such studies may depend mostly on the choice of model. The authors compared seven published models predicting the fluxes of $\mathrm{N}$ from wastewater, fertilizer and energy production to one estuary of Waquoit Bay (Massachusetts) and found a predicted wastewater contribution between 13 and $89 \%$. Based on their experience in the area, and supporting their findings through ${ }^{15} \mathrm{~N}$ isotopic measurements, Bower and Valiela (2001) made own simulations for the entire catchment. Not surprisingly, they found a strong correlation between population density and percentage of $\mathrm{N}$ from wastewater (Figure 1). In Waquoit Bay, the main technology for dealing with domestic wastewater is the septic tank and Bower and Valiela (2001) assumed $80 \%$ transfer of wastewater nitrogen to the aquifer. We expect that a system based on sewers without treatment plants will have higher transfer coefficients for $\mathrm{N}$ to the receiving water, whereas sewer systems with advanced N-elimination will have lower transfer coefficients. Since freshwater systems have a certain capacity for reducing the nitrogen load, detailed knowledge of the path of nitrogen before it reaches the coastal area in question is required in order to judge a given situation. Generally, Galloway et al. (2003) describe the nitrogen transfer potential of wetlands, streams, lakes and rivers as 'very high', and the denitrification potential of these same systems as 'moderate to high'.

Green et al. (2004) estimated the fate of wastewater nitrogen on a global scale (Table 2). Only about $6 \%$ is removed in wastewater treatment plants. A little more than half of the remaining nitrogen stems from sewer systems. Due to the rapid increase in the global urban population (ca. 5 billion projected for 2025 as compared to ca. 2.5 billion in the late 90'ties; UNEP, 1999), we assume that in future, more nitrogen will be transported in sewers, and possibly more nitrogen will be removed.

Ever since the eighties of the last century, there has been considerable uncertainty whether nitrogen or phosphorus limits algae growth in coastal areas. Due to this uncertainty, the Danish regulation from 1987 demanded reductions in $\mathrm{N}$ as well as in P loading to the North Sea (Harremoës, 1998). In the scientific literature, the idea prevails that in coastal areas of the temperate zone, nitrogen is the primary limiting element for algae growth, with widespread P-limitation during spring and also in some deeper parts of the coastal areas (e.g. Rabalais, 2002; Bowen and Valiela, 2001; Cloern, 2001). The authors all point out that coastal ecology is more complex than freshwater ecology, and that the shift in the N:P:Si ratio is part of the problem, not only increased levels of $\mathrm{N}$ and P. Downing et al. (1999) explain the importance of $\mathrm{N}: \mathrm{P}$ ratios by the fact that the $\mathrm{N}$-content of aquatic organism is 
relatively constant, compared to large variations in the P-content of different organisms. Cloern (2001) points out that the spectacular fish deaths, often perceived as the only detrimental effects of coastal eutrophication, are only the end result of many more subtle changes, most prominently the shift in algae populations. Such shifts may also have important economic consequences by themselves, e.g. the disappearance of eelgrass, supporting a number of commercially interesting fish species (Bowen and Valiela, 2001). The on-going discussion of the Baltic Sea problems, where the population shift towards nitrogen fixing cyanobacteria causes problems, shows that considerable disagreements with respect to the best management of coastal areas still exist. At least in the case of the Baltic Sea, high reductions in $\mathrm{P}$ as well as in $\mathrm{N}$ loading seem to be preferred (Pelley, 2006).

There is much less research on aquatic ecosystems in the tropics, but in a comprehensive review, Downing et al. (1999) conclude that more N-limitations occur in tropical than in temperate freshwater systems. Furthermore, the authors expect nitrogen to be more persistent in the tropics and therefore to have a larger impact in the marine ecosystems than observed in the temperate zone.

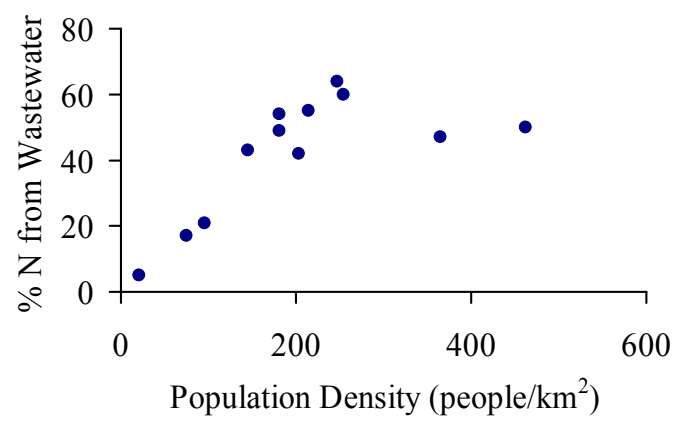

Figure 1 Percentage of total nitrogen reaching the estuaries of Waquoit Bay that stems from wastewater. Based on Bowen and Valiela (2001).

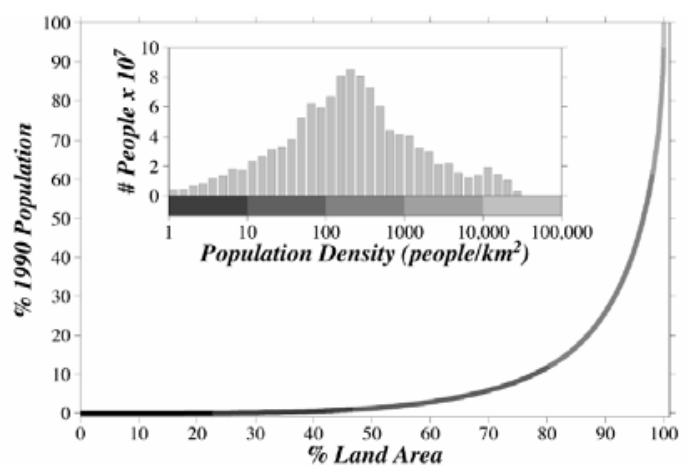

Figure $2 *$ Coastal population density distribution and Lorenz curve (<100 km from shore)
Table 2 Fate of nitrogen metabolized by humans on a global scale (Green et al., 2004)

\begin{tabular}{lll}
\hline Totally metabolized & Mt $_{N} /$ year & $21^{*}$ \\
Not in sewers & MtN/year $_{N}$ & 8.4 \\
In sewers & MtN/year $_{N}$ & 11.6 \\
Removed in treatment plants & Mt $_{N} /$ year & 1.3 \\
\hline
\end{tabular}

*Number corresponds to $10 \mathrm{~g} \mathrm{~N} /$ person/day and a mid1990 world population of 5.75 billion.

Table 3 Some aspects of the global phosphorus cycle (Mtp/year; according to Smil, 2000)

\begin{tabular}{lc} 
& $\mathrm{MT}_{\mathrm{p}} / \mathrm{year}$ \\
\hline Total erosion (incl. agriculture) & $\mathbf{3 0}$ \\
Total input to agriculture & $\mathbf{2 4 - 2 9}$ \\
Weathering + atmospheric deposition & $3-4$ \\
Organic recycling & $7-10$ \\
Synthetic fertilizers & $14-15$ \\
Total output from agriculture & $\mathbf{2 4 - 2 7}$ \\
Crops and crop residues & $11-12$ \\
Erosion & $13-15$ \\
$\mathbf{P}$ metabolized by humans, $\left.\mathbf{P}_{\mathrm{mh}} \mathbf{( *}^{*}\right)$ & $\mathbf{2 . 5}$ \\
\hline
\end{tabular}

(*)Assuming a daily excretion of $1.2 \mathrm{~g} \mathrm{P} /$ person and a mid-1990 world population of 5.75 billion.

* Copyright $(2003$ Coastal Education \& Research Foundation. From Journal of Coastal Research, by Small and Nicholls (2003). Reprinted with permission of Alliance Communications Groups, a division of Allen Press, Inc.

\section{THE PHOSPHORUS CYCLE.}

In contrast to $\mathrm{N}$, the $\mathrm{P}$ cycle can for all practical purposes be considered a one way flow dominated by erosion and the requirements of agriculture (Table 3; Smil, 2000). This makes phosphorus a scarce resource on a global scale, with available reserves for only about 100 years at the present rate of fertilizer consumption. However, the reserve base is three times bigger and large P-resources exist on the continental shelves and on seamounts (US geological survey, 2006). Quality, price and environmental consequences of mining rather than quantity are the main problem of phosphorus from a resource point of view. P-losses due to erosion in agriculture as reported by Smil (2000; Table 3) are based on an average erosion rate of $10 \mathrm{~kg}_{\mathrm{P}}$ per hectare. However, this erosion rate is 
rather to be expected in strongly eroded areas: Sharpley et al. (1995) reported a total phosphorus loss of $9.77 \mathrm{~kg} / \mathrm{ha} / \mathrm{y}$ in grass watersheds with extensive gully formation. On a global scale, accumulation of $\mathrm{P}$ in the agricultural soil might be higher than estimated by Smil (Table 3). Nevertheless, the data show that global phosphorus resource management is more a question of good agricultural practice than of sewage management. Since nutrient deficiency increases erosion, technologies favoring $\mathrm{P}$ (and $\mathrm{N}$ ) recycling would support good agricultural practice in areas where fertilizer application is limited by economic constraints, as for example in Africa (see Gruhn et al., 2000 for an overview over global nutrient mining of agricultural soil).

Even in Europe, however, there are good reasons to consider phosphorus recycling a positive aspect of human waste management. Due to the decreasing quality of mined phosphorus (higher levels of heavy metals) and higher environmental standards (e.g. regulation against recycling of gypsum waste from the production of phosphorus, among other things due to radioactivity and stricter thresholds for heavy metals in fertilizer), one must expect the price of phosphate to increase (see Smil, 2000 for an overview). In the long run, reducing losses of phosphorus from agriculture and increasing recycling of phosphorus will extend the time before even more expensive phosphorus with even higher environmental impacts has to be extracted from the resource base.

In the context of water pollution control, P-elimination is generally accepted as an efficient measure to prevent eutrophication of lakes, but the relevance for coastal areas is still controversial. The European Environment Agency (2005) estimates that the major phosphorus load to the aquatic environment in Europe stems from wastewater; on a global scale the numbers are very uncertain.

Originally, phosphorus elimination was introduced to protect freshwater lakes and was very often successful. However, with increasing urbanization, conventional technology (resulting in an effluent concentration of about $0.2 \mathrm{~g}_{\mathrm{Pm}}{ }^{-3}$ ) may not be sufficient everywhere. In Lake Greifensee in Switzerland, phosphorus still causes problems and $52 \%$ of biologically available P stems from wastewater: $20 \%$ from treated wastewater, $16 \%$ from combined sewers overflow (CSO), and $16 \%$ from storm water discharges (Meier, 2003). The author discusses measures for a reduction in the total P-loading, but does not expect to reach the desired water quality of the lake. In Lake Dianchi, Kunming, China, we observe a similar situation. Huang et al. (2007) showed that even with best available wastewater management technology and equal efforts from agriculture and industry, it is not possible to reach the official goals for the P-loading of the lake.

Already in 1987, P-control was introduced in Denmark to protect the North Sea (Harremoës, 1998). The effects of phosphorus in coastal areas may be slow to manifest, but can be difficult to reverse. An example is the Baltic Sea where phosphorus rich sediments built up over the last decades and strict P-control is recommended to restore water quality over the next decades (Conley et al., 2002). In the tropics, the situation is similar. Many coastal ecosystems are limited by phosphorus, including precious mangrove and reef ecosystems (Downing et al., 1999), and these authors assume the effects of eutrophication to be worse in the tropical than in the temperate zone. Since fish is the primary source of protein for one billion people, especially in the southern hemisphere (UNEP, 1999), a possible breakdown of aquatic wildlife will also have more serious consequences for people in this area.

\section{A GENERAL STRATEGY FOR ADVANCED NUTRIENT MANAGEMENT}

From the findings above, we conclude that on a global scale, advanced nutrient management is a question of water pollution control, economy and environmental effects of fertilizer production and application, rather than nutrient scarcity. In some parts of the world, severe economic constraints on nutrient application with detrimental effects on society and environment alike, call for a strong focus on nutrient recycling from human waste as part of the agenda for sustainable development 
(see e.g. Wilderer, 2005). In other areas, nutrient recycling may be a positive side aspect, but this must be evaluated from an integrated point of view. For water pollution control, phosphorus removal is important in freshwater and coastal ecosystems alike, whereas nitrogen removal is mainly (but not exclusively) important for coastal areas. Although agriculture is also an important source of nutrients, evidence from Europe and the USA shows that nutrient removal from wastewater is a necessary and effective measure to abate water pollution. Since on a global scale, only about $6 \%$ of nitrogen from the human metabolism is eliminated in treatment plants, there is a huge scope for improved $\mathrm{N}$-control. We assume the potential for $\mathrm{P}$ to be in the same order of size.

It is by now generally established that marine and coastal ecosystems provide a large range of benefits to humans and that these ecosystems are deteriorating fast, also due to the fact that population densities are high and growing in coastal areas (UNEP, 2006; see also Figure 2). Since the effects of nutrient loading on coastal waters are slow to manifest, the rapid urbanization in these areas will lead to increased problems in the future, which can only be circumvented if strict nutrient management is implemented (Mee, 2006). For freshwater systems, decisions on wastewater management are easier due to the closer relation between cause and effect. However, uncertainties in source modeling, the effect of phosphorus accumulation and more prevalent N-limitations in tropical freshwaters are still complicating factors in such decision processes. Since the world population will increase dramatically in the next decades with a large shift toward urban areas, we predict that on a global scale highly effective nutrient containment technologies will gain in importance. Since climate change will probably lead to dryer summers at least in continental and southeastern Europe (Rowell and Jones, 2006), we expect water pollution problems to increase also in Europe, leading to stricter emission requirements for nutrients also in Europe.

It is not an easy task to determine in general whether conventional end-of-pipe or new technologies based on source separation hold most promise for efficient nutrient management. Since source separating technologies are at a very early point of development, traditional cost-benefit analyses are still difficult. Basically, both technologies can do the same things, although source separating technologies hold more promise for very stringent nutrient emission targets and nitrogen recycling. Experience with source control of phosphate in detergents show that measures at the source may in fact be very efficient (Siegrist and Boller, 1999). In nutrient deficient areas like some parts of Africa where fertilizers are several times more expensive than elsewhere, but at the same time dramatically needed to feed an increasing population and to preserve valuable farmland (Gruhn et al., 2000), source separation seems the only logical step in order to ensure good management of a local resource (see also Wilderer, 2005). Although in this case, simple source separation technologies for rural areas will be highly valuable, there is an even larger impetus to develop modern technologies for high density areas, where effective nutrient containment and recycling could make a huge difference for water pollution control as well as for the surrounding agriculture.

\section{PERFORMANCE AND RESOURCE MANAGEMENT OF DIFFERENT TECHNOLOGIES.}

Below we compare one source separating technology, the NoMix technology, and different conventional technologies with respect to removal efficiencies and energy consumption. We also discuss the issues of micropollutants, sludge production and economy. From Table 4, we see that NoMix technology alone or in combination with primary treatment, chemical precipitation or biological treatment with a low sludge age will answer the case for high $\mathrm{P}$ and especially high $\mathrm{N}$ removal. If NoMix technology is applied without combination with an end-of-pipe technology, a parallel phosphate ban and/or some sort of feces management is necessary for substantial reduction of P-emissions. We suggest that in areas with little existing infrastructure, it makes more sense to apply NoMix technology and feces management directly instead of installing sewers, which are in most cases not followed by the installation of nutrient removing wastewater treatment plants. Well managed NoMix technology will rapidly improve water quality instead of the typical history of 
sewers decreasing water quality before treatment plants may eventually improve it again. Also a combination of simplified sewers and NoMix technology would make it relatively easy to upgrade such a system with simplified wastewater treatment, e.g. sedimentation with or without chemical precipitation.

If we look at energy issues, Wilsenach and van Loosdrecht (2006) show that NoMix technology transforms an advanced nutrient elimination plant from an energy consumer of about $11 \mathrm{~W} /$ person of primary energy into an energy producer, producing about $2 \mathrm{~W} /$ person. Nowak (2003) sets much more stringent benchmarks for the energy efficient Austrian plants $(<1 \mathrm{~W} /$ person of external electrical energy $\approx<3 \mathrm{~W} / \mathrm{p}$ primary energy), partly due to less stringent emission standards, but nevertheless reducing the NoMix potential of energy economy. However, some of the energy savings claimed by Novak (2003) will also result in an increase of the energy production reported by Wilsenach and van Loosdrecht (2006). If urine is recycled as fertilizer, more energy saving is possible if the total recycling energy is smaller than the amount of energy required for the production of synthetic $\mathrm{N}$ and $\mathrm{P}$ fertilizer. As compared to the average $45 \mathrm{MJ} / \mathrm{kg}_{\mathrm{N}}$ primary energy used for nitrogen fertilizer production in Europe, Maurer et al. (2003) report on existing technologies increasing the nutrient concentration in urine 5-10 fold with an energy demand of around $30 \mathrm{MJ} / \mathrm{kg}_{\mathrm{N}}$. However, the fate of nitrogen may be more important than energy (see Galloway, 2003 for an overview of nitrogen transformation in the environment). In areas with nitrogen surplus, well-managed nitrogen removal from urine (Udert et al., 2003) is a much better solution. In nutrient deficient areas, the case for recycling is clear, and increasing energy prices will make nitrogen recycling even more rewarding in future. Where recycling makes sense, one should aim at producing a fertilizer product with a high uptake rate by plants.

Table 4 Comparison of estimated elimination efficiencies [\%] of wastewater treatment plants (WWTP) versus NoMix technology. We only consider domestic wastewater and assume $5 \%$ loss of raw wastewater in combined sewers overflow, $100 \%$ connection, and European standards.

\begin{tabular}{|c|c|c|c|c|}
\hline & \multicolumn{3}{|c|}{ Typical removal efficiencies (\%) } & \multirow{2}{*}{$\begin{array}{l}\mathrm{NH}_{4}{ }^{+} \text {effluent } \\
\text { concentration }\end{array}$} \\
\hline & COD & $\mathrm{N}$ & $\mathrm{P}$ & \\
\hline WWTP, primary treatment & 30 & 5 & $5-15$ & high \\
\hline WWTP, chemical precipitation $\left({ }^{*}\right)$ & $60-75$ & $15-30$ & $85-95$ & high \\
\hline WWTP, sludge age 2 days & 75 & 25 & $15-85$ & high \\
\hline WWTP, sludge age 8-10 days & 90 & 25 & $15-85$ & low \\
\hline WWTP, sludge age $>12$ days & 90 & $50-75$ & 15-85 & low \\
\hline WWTP, sludge age $>12$ days + organic $C$-source & 90 & 85 & $15-85$ & low \\
\hline WWTP + P-filter & see above & see above & $>85$ & see above \\
\hline NoMix technology (90 \% separation efficiency) & 15 & $70-80$ & $15-50$ & low \\
\hline
\end{tabular}

(*) From Ødegaard (1992); numbers from article corrected assuming $5 \%$ loss of raw wastewater in CSOs.

Sludge production is an important and often forgotten aspect of wastewater treatment. As long as sludge could be cheaply disposed of in agriculture, P-recycling could at least be postulated. However, the presence of heavy metals and questionable organic compounds combined with a suboptimal plant availability of the phosphorus reduces the acceptance of sludge reuse drastically. In Switzerland, all sewage sludge is now incinerated and hence the large amount of incineration residue due to the products of chemical precipitation becomes more important.

NoMix technology is not only a question of nutrients; urine also contains a multitude of organic compounds due to the human detoxification system in the kidneys. Urine contains about $15 \%$ of the COD found in wastewater, corresponding roughly to $30 \%$ of DOC. The endogenous urine compounds are part of the problem of combined sewers overflow (CSO), and exhibited an 80 times stronger effect in one ecotoxicity test than a defined mixture of pharmaceuticals alone (Escher et al., 
2006). Furthermore, synthetic hormones and pharmaceutical residues are largely contained in urine. In a quantitative assessment of 212 parent drugs, Lienert et al. (subm., this issue) found that on average $64 \%$ of these pharmaceuticals are excreted in urine, albeit with extremely large variations. However, the efficiency of urine source separation on the fate of micropollutants also depends on the relative toxicity of the feces and urine fraction, respectively, and the fate of particulate matter in sewers and wastewater treatment plants. Ecotoxicologal modeling of 30 drugs and their human metabolites indicated that urine source separation could successfully decrease the ecotoxicological risk of some, but certainly not all drugs (Lienert et al., in press). The authors estimate that roughly equal average risks are contained in urine and feces. Rossi et al. (subm.) point out that NoMix technology would allow for a stronger focus on particulate matter in CSO management, a beneficial strategy for both P-elimination and the elimination of micropollutants contained in feces. Naturally, the same strategy would apply for treatment plants.

As for every new technology, economy is the main unknown and at present, NoMix technology can not compete with conventional end-of-pipe technology in this respect. Maurer et al. (2005) set approximate benchmarks of 260-440 US\$ per capita for the investment in NoMix installations, assuming the same operation and maintenance costs as for central plants with present standard nutrient removal, but without counting the savings for disposal of sludge without precipitation products. We estimate that this is a challenging but not impossible benchmark and that increasing demands on effluent quality will render NoMix technology even more interesting in the future.

\section{CONCLUSION}

We conclude that on a global scale nutrient management is one of the most important issues of advanced sanitation, with large implications for water pollution control, resource management, and sustainable development. The scientific literature supports concomitant $\mathrm{N}$ and $\mathrm{P}$ removal to protect coastal areas and statistics show that on a global scale there is a huge potential for improved nutrient removal. Nutrient mining from agricultural soil due to economic constraints is an immense sustainability issue that could be much helped with effective nutrient recycling from human waste, especially from urban areas. Source separating technologies, like the NoMix technology, have a large potential for resource efficient nutrient removal and recycling. Due to present trends towards urbanization, especially of coastal areas, and climate change we expect much more stringent nutrient emission targets, favoring source separating technologies, globally as well as in Europe. We see a large potential for the development of modern source separating technologies for urban areas and expect that these could rapidly become economically competitive, also in Europe.

\section{REFERENCES}

Bowen, J.L. and Valiela, I. (2001) The ecological effects of urbanization of coastal watersheds: historical increases in nitrogen loads and eutrophication of Waquoit Bay estuaries. Can. J. Fish. Aquat. Sci. 58, 1489-1500.

Cloern, J.E. (2001) Our evolving conceptual model of the coastal eutrophication problem. Mar. Ecol.-Prog. Ser. 210, 223-253.

Downing, J.A. and 12 further authors (1999) The impact of accelerating land-use change on the N-cycle of tropical ecosystems: current conditions and projected changes. Biogeochemistry 46, 109-148.

Conley, D.J.; Humborg, C.; Rahm, L.; Savchuk, O.P. and Wulff, F. (2002) Hypoxia in the Baltic Sea and basin-scale changes in phosphorus biogeochemistry. Environ. Sci. Technol. 36(24), 5315-5320.

Escher, B.I., Pronk, W., Suter, M.J.-F. and Maurer, M. (2006) Monitoring the removal efficiency of pharmaceuticals and hormones in different treatment processes of source-separated urine with bioassays. Environ. Sci. Technol. 40(16), 5095-5101.

European Environment Agency (2005) Source apportionment of nitrogen and phosphorus inputs into the aquatic environment. EEA Report No 7. ISSN 1725-9177.

Galloway, J.N. and 14 further authors (2004) Nitrogen cycles: past, present, and future. Biogeochemistry 70, 153-226.

Galloway J.N., Aber, J.D., Erisman, J.W., Seitzinger, S.P., Howarth, R.W., Cowling, E.B. and Cosby, B.J. (2003) The nitrogen cascade. Bioscience 53(4), 341-356. 
Green, P.A., Vörösmarty, C.J., Meybeck, M., Galloway, J.N., Peterson, B.J. and Boyer, E.W. (2004) Pre-industrial and contemporary fluxes of nitrogen through rivers: a global assessment based on typology. Biogeochemistry 68, 71-105.

Gruhn, P., Goletti, F. and Yudelman, M. (2000) Integrated nutrient management, soil fertility, and sustainable agriculture: current issues and future challenges. International Food Policy Research Institute, 2033 K Street, N.W., Washington, D.C. 20006 USA. http://www.ifpri.org/2020/dp/2020dp32.pdf.

Harremoës, P. (1998) The challenge of managing water and material balances in relation to eutrophication. Water Sci. Technol. 37(3), 9-17.

Huang, D.-B., Bader, H.-P., Scheidegger, R., Schertenleib, R. and Gujer, W. (2007) Confronting limitations: new solutions required for urban water management in Kunming City. J. Environ. Manage. 84(1), 49-61.

Kroiss, H. (2004) What is the potential for utilizing the resources in sludge? Water Sci. Technol. 49(10), 1-10.

Lienert, J., Bürki, T. and Escher, B.I. (subm.) Reducing micropollutants with source control: substance flow analysis of 212 pharmaceuticals in feces and urine. Presented at the IWA 'Advanced Sanitation' conference, 12.-13. March 2007, Aachen, Germany. Submitted to Water Sci. Technol.

Lienert, J., Güdel, K. and Escher, B.I. (in press) Screening method to assess the ecotoxicological hazard of 42 pharmaceuticals after metabolism and a source control measure. Accepted for publication in Environ. Sci. Technol.

Maurer, M., Rothenberger, D. and Larsen, T.A. (2005) Decentralised wastewater treatment technologies from a national perspective: At what cost are they competitive? Water Sci. Technol.: Water Supply 5(6), 145-154.

Maurer, M., Schwegler, P. and Larsen, T. A. (2003) Nutrients in urine: energetic aspects of removal and recovery. Water Sci. Technol. 48(1), 37-46.

Mee, L. (2006) Reviving dead zones. Scientific American 295(5), 54-61.

Meier, W. (2003) Phosphorbelastung des Greifensees: Aktuelle Belastungen, Reduktionspotenziale und deren Kosten, Auswirkungen von Sanierungsmassnahmen auf den Seezustand; Office for waste, water, energy, and air of the Canton of Zurich (AWEL; Switzerland), http://www.gewaesserqualitaet.zh.ch/internet/bd/awel/gs/gq/de/doku/doku_seen.html (in German).

Nowak, O. (2003) Benchmarks for the energy demand of nutrient removal plants. Water Sci. Technol. 47(12), 125-132. Ødegaard, H. (1992) Norwegian experiences with chemical treatment of raw wastewater. Water Sci. Technol. 25(12), 255-264.

Pelley, J. (2006) Do nitrogen cuts benefit the Baltic Sea? Environ. Sci. Technol. 40(15), 4538-4539.

Rabalais, N.N. (2002) Nitrogen in aquatic ecosystems. Ambio 31(2), 102-112.

Rossi, L., Lienert, J. and Larsen, T. A. (subm.) Real-life efficiency of urine source separation: experience from households and an institution. Submitted to Water Res.

Rowell, D.P. and Jones, R.G. (2006) Causes and uncertainty of future summer drying over Europe. Clim. Dyn. 27(2-3), 281-299.

Sharpley, A.N., Hedley, M.J., Sibbesen, E., Hillbricht-Ilkowska, A., House, W.A., Ryszkowski, L. (1995) Phosphorus transfers from terrestrail to aquatic ecosystems. In: Tiessen H. (ed.) Phosphorus in the global environment: transfers, cycles and management. Wiley\&Sons, Chichester.

Siegrist, H. and Boller, M. (1999) Auswirkungen des Phosphatverbots in den Waschmitteln auf die Abwasserreinigung in der Schweiz. Korrespondenz Abwasser 46(1), 57-65 (in German).

Small, C. and Nicholls, R.J. (2003) A global analysis of human settlement in coastal zones. J. Coast. Res. 19(3), 584599.

Smil, V. (2000) Phosphorus in the environment: natural flows and human interferences. Annu. Rev. Energ. Environ. 25, 53-88.

UNEP (2006) Marine and coastal ecosystems and human well-being: A synthesis report based on the findings of the Millennium Ecosystem Assessment. UNEP. 76 pp. www.MAweb.org.

US Geological Surveys (2006) http://minerals.usgs.gov/minerals/pubs/commodity/phosphate rock/index.html.

Udert, K. M., Fux, C., Münster, M., Larsen, T. A., Siegrist, H. and Gujer, W. (2003) Nitrification and autotrophic denitrification of source-separated urine. Water Sci. Technol. 48(1), 119-130.

UNEP (1999) GEO-2000. Global Environmental Outlook. ISSN: $0 \quad 1366 \quad 8080$. Available at http://www.unep.org/geo2000.

Valiela, I., Bowen, J.L. and Kroeger, K.D. (2002) Assessment of models for estimation of land-derived nitrogen loads to shallow estuaries. Appl. Geochem. 17, 935-953.

Wilderer, P.A. (2005) UN water action decade: a unique challenge and chance for water engineers. Water Sci. Technol. 51(8), 99-107.

Wilsenach, J.A. and van Loosdrecht, M.C.M. (2006) Integration of processes to treat wastewater and source-separated urine. J. Environ. Eng.-ASCE 132(3), 331-341. 